International Review of Research in Open and Distributed Learning Volume 21, Number 1

January - 2020

\title{
Distance Learners' Experiences of Silence Online: A Phenomenological Inquiry
}

Leslie Duran, M.S., EdD

Department of Occupational Science and Occupational Therapy, Faculty of Medicine, The University of British Columbia

\begin{abstract}
Although learner silence in face-to-face classrooms has been the topic of considerable research interest, relatively little investigation has been done into learners' experience of silence in distance education. Guided by a phenomenology of practice approach, this study explores the lived experiences of online silence, using interview data gathered from 12 graduate students who were engaged in cohort-based distance learning.

Iterative rounds of a whole-part-whole interpretive process were used to identify key themes that emerged regarding the participants' lived experiences. The findings highlight that silence is a complex, multifaceted phenomenon that was both enacted and received by the participants. Speaking out online was done carefully, sometimes with partial voice and sometimes in fuller voice, sometimes as an obligation and other times with a sense of spontaneity and connection.

The six themes that emerged were as follows: (a) learners enact purposeful silence; (b) learners absorb silence from others; (c) learners perceive, and use, silence as demarcation; (d) learners experience silence within voice; (e) learners use deliberate, complex strategies while engaging in online discourse; and (f) learners hear each other in a trusted community. These six themes give new understandings to the experience of online silence. They reflect the multifaceted and nuanced aspects of the phenomenon and have implications for distance education instructors, learners, and curriculum developers.
\end{abstract}

Keywords: distance education, silence, phenomenology of practice, learner experience, online communication, cohort 


\section{Introduction}

I expect to meet some people here. No one is here, yet. I start "talking." No one responds. Where do my words go? I feel alone. (Adams \& van Manen, 2006, p. 10)

Social constructivist approaches to learning assert that interaction is a fundamental requirement for the development of community, the creation of meaning, and the promotion of learning (Bates, 2015; Conrad, 2014). In many distance education courses, the majority of interaction occurs in asynchronous, text-based discussion forums. Instructors and students post messages and respond to other people's postings, resulting in a threaded discussion. In these threaded discussions, if an instructor or learner does not post or is delayed in responding to another's post, the absence of communication comes across as silence (Xin \& Feenberg, 2006).

Silence from learners can be distressing, and the underlying reasons for the silence may be difficult for instructors to interpret (Beaudoin, 2002; Benfield, 2000). When silence occurs online, members of the learning community may be left to wonder whether the silence is indicative of agreement, disinterest, absence, uncertainty, or alienation (Gradinaru, 2016; Xin \& Feenberg, 2006). A body of research has centred on learners who are engaged in online discussions without visibly posting in them. These learners have at times been referred to as lurkers (Beaudoin, 2002; Taylor, 2002). Kreijns, Kirschner, and J ochems (2003) describe a parasitic form of lurking called social loafing. Other researchers ascribe more positive descriptors for students engaged in this behaviour, including witness learners (Fritz, 1997) and vicarious interactors (Sutton, 2001); there is evidence that these learners are cognitively engaged in the discussion even if they do not interact with others online.

When the topic of silence online appears in the literature, it is most commonly presented as an emergent theme from a different primary research focus, such as a focus on factors that influence participation in online learning activities (cf. Antonacci, 2011; Brown, 2011; Conrad, 2002). One exception is found in the work of Zembylas and Vrasidas (2007), who concluded that while online silences arise from learner nonparticipation, confusion, and marginalization, silence is also a by-product of thoughtful reflection. Further investigation into the "meaning and significance of silence in online education" (Zembylas \& Vrasidas, 2007, p. 20) is needed.

The purpose of the present research study is to understand the experience, embodiment, and meaning of online silence as a phenomenon lived by online graduate distance learners. The research question was as follows: What are thelived experiences of online silence for learners who aremembers of distancelearning communities? This question emerged from the author's own experiences of online silence as a distance learner and a distance educator.

\section{Research Methodology}

The study was guided by phenomenology of practice (van Manen, 1990, 2014), a hermeneutic (interpretive) phenomenology used to explore phenomenological questions that arise out of daily occupational 
experiences (van Manen, 2011, 2014). Researchers using this approach are descriptive interpreters (KoroLjungberg, Yendol-Hoppey, Smith, \&Hayes, 2009).

Phenomenological inquiry involves the use of reduction (van Manen, 2011), which is the deliberate setting aside of one's own expectations and attitudes in order to focus on the lived experiences of the participants. In Husserlian phenomenology, reduction is known as epoché or bracketing (LeVasseur, 2003; van Manen, 2014). van Manen (2011) differentiates various approaches to reduction, including the eidetic reduction and the hermeneutic reduction.

The eidetic reduction (also known as eidos or essence) focuses on the researcher reflectively becoming aware of aspects of the phenomenon that make it unique from other experiences. The aim of the eidetic reduction is not a universal generalization about the phenomenon but an exploration of possible meanings that are by nature incomplete and tentative (van Manen, 2014). Part of completing the eidetic reduction is to explore variations on the phenomenon by comparing it "with other related but different phenomena" (van Manen, 2014, p. 230).

Similar to the concept of bracketing, the hermeneutic reduction requires researchers to reflectively give attention to any assumptions that emerge when writing a manuscript, including not interpreting emerging themes too quickly. The researcher needs to mindfully and actively set aside personal understandings of the phenomenon to focus on the participants' lived experiences (van Manen, 2014). The researcher's role is to explore how the phenomenon is experienced in the participants' everyday lives and to write a text that provides readers with a deeper understanding of the phenomenon under investigation (Vagle, 2014; van Manen, 1990).

\section{Participants}

Ethical approval for the study and recruitment strategy was obtained from the Research Ethics Board at Athabasca University. Potential participants were given a written description of the study and an informed consent letter for signature to inform them as to the purpose of the study, assurance of confidentiality, and acknowledgement that they could withdraw participation at any time without penalty or consequence.

Inclusion criteria were that participants

1. were learners in a cohort-based postsecondary distance education course or program of study that had an expectation of participation in asynchronous, text-based discussion as a significant component of the interaction;

2. had completed at least two online courses that required the use of asynchronous, text-based discussion; and

3. were distance education students at the time of the initial interview. 
Exclusion criteria were that participants could not be students in online classes taught by the author, nor could they be peer members of the author's doctoral program cohort.

Recruitment occurred through personal contacts $(n=3)$ and by approaching instructors in online courses taught at a western Canadian university $(\mathrm{n}=9)$. In total, 12 participants were recruited, an appropriate number for phenomenological research (Creswell, 2013; Dukes, 1984). Self-reported demographic data were collected to guide ongoing purposive sampling and to ensure that a range of voices was included (Angen, 2000). Demographic characteristics of the participant group are summarized in Table 1.

Table 1

Demographic Characteristics of Participants

\begin{tabular}{|c|c|c|c|}
\hline & & $\mathrm{n}(\%)$ & \\
\hline \multirow[t]{2}{*}{ Age range } & $40-49$ & $50-59$ & $60-69$ \\
\hline & $6(50)$ & $4(33.3)$ & $2(16.7)$ \\
\hline \multirow[t]{2}{*}{ Discipline } & $\begin{array}{l}\text { Education } \\
10 \text { (83.3) }\end{array}$ & $\begin{array}{l}\text { Business } \\
\text { administration }\end{array}$ & $\begin{array}{l}\text { Health } \\
\text { management }\end{array}$ \\
\hline & & $1(8.3)$ & $1(8.3)$ \\
\hline \multirow{2}{*}{$\begin{array}{l}\text { Time as a distance } \\
\text { learner }\end{array}$} & $1-<5$ years & $5-9$ years & $>9$ years \\
\hline & $7(58.3)$ & $3(25)$ & $2(16.7)$ \\
\hline \multirow[t]{2}{*}{ Sex } & Male & Female & \\
\hline & $3(25)$ & $9(75)$ & \\
\hline \multirow[t]{2}{*}{ Program of study } & Master's degree & Doctorate & \\
\hline & $2(16.7)$ & 10 (83.3) & \\
\hline
\end{tabular}

\section{Trustworthiness}

This study incorporated the following elements (Angen, 2000) to support the trustworthiness of the findings:

1. Alignment of research question, approach, and method. The research question is phenomenological in nature. The method followed phenomenological analysis of participant interviews, with the main knowledge producers being the participants (Koro-Ljungberg et al., 2009).

2. Trustworthiness of transcriptions. The researcher used repeated confirmations to ensure transcription accuracy, including member checking. 
3. Peer review. The researcher engaged in ongoing peer review with a fellow phenomenological researcher, meeting regularly to critically discuss the methodology and unfolding research process.

4. Dissident perspectives. Some participants in the study offered "outlier" or dissident experiences from those described by most other participants. Differing voices add richness to the data and increase the trustworthiness of the findings (Bazeley, 2009; McPherson \& Thorne, 2006).

\section{Data-Gathering Methods}

Prior to beginning data collection, the researcher initiated keeping a reflexivejournal to (a) explore her own experiences and expectations around the nature and meaning of online silence (groundwork for the hermeneutic reduction), and (b) compare the essential nature of silence to related experiences such as loneliness and quietude (groundwork for the eidetic reduction).

The primary data-gathering method was open-ended, loosely structured oral interviews, which were audio recorded. The interviews were conducted by phone, video call, or in person, based on each participant's preference. One follow-up interview was conducted by e-mail.

Two of the participants did not have a second interview (one did not respond to requests to schedule the second interview; the other was travelling out of the country and was unavailable during the time remaining for gathering data). Data were therefore gathered from a total of 22 interviews. Initial interviews were approximately one hour in duration; follow-up interviews were approximately 30 minutes.

The interviews were conversational in nature but grounded by the main research question with an aim to elicit personal life vignettes that illustrated the participants' own experiences of silence online, known as lived experience descriptions (van Manen, 2014). Subsequent interviews provided an opportunity to probe more deeply into experiences that were touched on in the first interview and on nascent topics emerging from early stages of the iterative process of interpreting the data (Vagle, 2014). The second interview also functioned as a means of prolonging engagement with the participants, adding to trustworthiness (Creswell, 2013).

The researcher manually transcribed each interview. Participants were given the option of reviewing the interview transcripts to check for accuracy and to correct transcription errors if needed. Five participants (41.7\%) chose to review their transcripts, one participant filled in some words or phrases in the transcript that had been difficult to understand on the audio recording, another added a few additional comments and minor points of clarification, and the other three participants had no suggestions for changes to their transcripts. The researcher assigned each participant a pseudonym to maintain confidentiality.

The researcher used the following iterative process, modified from Vagle (2014), to engage with and interpret the data:

1. Reorient to the interview transcript by reading it holistically. 
2. Reread the interview transcript line by line, taking notes and marking noteworthy excerpts.

3. Compose a lengthy reflective journal entry.

4. Repeat steps 1, 2, and 3 for additional interview transcripts as they became available.

5. Craft follow-up questions for subsequent participant interviews.

6. Complete a second line-by-line reading to begin to articulate meanings.

7. Complete reflective journal entries for each interview based on new insights gleaned from step 6 .

8. Complete a third line-by-line reading to further articulate each part identified in step 6 for each participant.

9. Begin to coalesce the voices of multiple participants around specific topics as possible precursors to larger themes.

10. Repeat steps 8 and 9 to identify themes and give these themes preliminary titles.

This iterative process of interpreting the data required careful writing and rewriting in alternating processes of reflection and action. During the reflective processes, the researcher attended to the hermeneutic reduction by (a) asking herself if the patterns emerging in the data were consistent with what she would have expected to find, and (b) paying particular attention to lived experience descriptions that were unexpected, gave new insights, or were divergent in nature from what other participants had described. Exploring the unexpected and divergent experiences through writing and reflection in steps 7 through 10 was a means of furthering the eidetic reduction. In step 9, the researcher wrote descriptions of 16 different emerging topics and reflected on which parts of them were essential aspects of the participants' experiences of silence online (examples of these emerging topics include authenticity, authority, conflict, feeling safe, muting voice, and telling personal stories). In step 10, the researcher distilled these topics into themes, carefully selecting precise wording. Selected examples of participant quotes that support each theme are provided in Table 2.

\section{Table 2}

\section{Selected Participant Quotes}

\begin{tabular}{|c|c|}
\hline Quote & Theme \\
\hline $\begin{array}{l}\text { "I allow myself to use silence to selectively engage with the things that really } \\
\text { speak out to me." (Tamara) } \\
\text { "I tend to watch a bit before I contribute. I'll read other posts. What are they } \\
\text { saying? Are they thinking the same way I am?" (Frances) } \\
\text { "There are times that I might scribe something based on my first instinct, } \\
\text { but after taking some time to reflect on it, I choose not to post it ... I don't } \\
\text { want to be seen as somebody who can't regulate their emotions." (Becca) }\end{array}$ & $\begin{array}{l}\text { Learners enact purposeful } \\
\text { silence. }\end{array}$ \\
\hline
\end{tabular}




\begin{tabular}{|c|c|}
\hline $\begin{array}{l}\text { "When it's silent, I wonder whether or not I've been heard. Or if I said } \\
\text { something that someone seriously disagrees with or is upset with and } \\
\text { doesn't know how to respond to." (Naomi) } \\
\text { "You put something up and people don't respond. You go on to another } \\
\text { post, and they've got 12, } 15 \text { replies, and you're sitting out there all alone ... } \\
\text { That silence devalues what I contributed." (Frances) } \\
\text { "Of anybody in the class, if you're asking a question, the teacher should be } \\
\text { the one responding." (Mark) } \\
\text { "If you don't get a response on forums, that's just normal." (Thomas) }\end{array}$ & $\begin{array}{l}\text { Learners absorb silence from } \\
\text { others. }\end{array}$ \\
\hline $\begin{array}{l}\text { "If you challenge some professors with something that's super brand new, } \\
\text { or you bring in a different point of view that isn't part of their construct, } \\
\text { they don't necessarily want to consider it." (Naomi) } \\
\text { "When I feel like I'm in a safe place within my community ...it's easier for me } \\
\text { to break through the silence and feel confident to share." (Tamara) } \\
\text { "Sometimes we got off on small tangents. We were exploring the boundaries } \\
\text {...In our minds, we were moving [the discussion] forward. In the } \\
\text { professor's mind, we were off task ... It was a really interesting dichotomy } \\
\text { between us taking ownership, and her calling it back and saying, 'No, no, } \\
\text { no! This isn't how we do this."” (Naomi) }\end{array}$ & $\begin{array}{l}\text { Learners perceive, and use, } \\
\text { silence as demarcation. }\end{array}$ \\
\hline $\begin{array}{l}\text { "I'm in a same-sex relationship and I would never post that online, because } \\
\text { I'm not sure how that's received at the other end of the world. I am much } \\
\text { less descriptive about gender pronouns, keeping that a little more nebulous. } \\
\text { I won't show that part of myself in the online discussion." (J ane) } \\
\text { "When [an instructor's] answer doesn't really answer your question ... it's a } \\
\text { response, but it was a silence, if you know what I mean." (Frances) }\end{array}$ & $\begin{array}{l}\text { Learners experience silence } \\
\text { within voice. }\end{array}$ \\
\hline $\begin{array}{l}\text { "I want to give each person the time and merit that they deserve. When a } \\
\text { post is more than } 750 \text { words, I disengage from that, because I get annoyed } \\
\text { that it is so long. I try to reply back to people that post somewhere between } \\
200 \text { and } 400 \text { words. I really focus on giving them a good response." (Karen) } \\
\text { "If you put it in writing, there's a record of it, right? So I always wanted to } \\
\text { be careful that what I wrote was accurate." (Katrina) } \\
\text { "Sometimes posting first means you just dump what's on your brain right } \\
\text { away. Whereas going in later on forced you to read everyone else's posts, } \\
\text { and assimilate their thoughts, and try to get a response." (Mandy) }\end{array}$ & $\begin{array}{l}\text { Learners use deliberate, } \\
\text { complex strategies while } \\
\text { engaging in online discourse. }\end{array}$ \\
\hline $\begin{array}{l}\text { "There were times that I was excited to go in, because there was a really, } \\
\text { really good conversation going on between myself and a couple other } \\
\text { people. I was just really interested in their responses." (Katrina) } \\
\text { "You start talking about real things that happen in the workplace, that you } \\
\text { would never talk about publicly ... Even the teachers would share some very } \\
\text { personal experiences that would help to foster that idea of safety." (Mark) } \\
\text { "There's a sense that we are trying to help each other through and looking } \\
\text { out for each other." (J onathon) }\end{array}$ & $\begin{array}{l}\text { Learners hear each other in a } \\
\text { trusted community. }\end{array}$ \\
\hline
\end{tabular}

\section{Findings: Six Themes of Learner Experience of Silence Online}

Following data collection and the iterative process of interpreting the findings, six themes emerged regarding the learners' experiences of silence online: (a) learners enact purposeful silence; (b) learners absorb silence from others; (c) learners perceive, and use, silence as demarcation; (d) learners experience silence within voice; (e) learners use deliberate, complex strategies while engaging in online discourse; and 
(f) learners hear each other in a trusted community. These six themes reflect the complex, sometimes nuanced, aspects of the participants' experiences of silence and voice online.

The first two themes reflect participants' experiences of silence itself. The third and fourth themes address areas of transition between voice and silence. Finally, the last two themes address participants' experiences of coming out of silence to speak out online. The six themes together capture descriptions of the participants' rich lived experiences of being silent themselves, receiving silence from others, and speaking out online either in muted or full voices.

\section{Theme 1: Learners Enact Purposeful Silence}

Participants described times when they were aware that they were being silent online. When participants kept silence, they did so intentionally, with purpose. The silent times were not quiet or passive times; rather, participants described being busy in thought or action during these times.

Participants frequently chose to enact silence for one of two distinct but overlapping reasons, which can be considered as silence as means of and silence as time for. When participants used online silence as means of, they used it as an intentional method of accomplishing something else, such as balancing priorities, identifying learning needs, preventing poorly thought-out ideas from being posted, avoiding redundancy in the discussion threads, maintaining professional etiquette, and regulating their emotions. Enacting silence online was also at times a means of "biting one's tongue" to prevent conflict from escalating. This use of silence in the presence of conflict is similar to that identified by Conrad (2002).

During other times, participants enacted silence online in order to allow time for other things to happen. Participants described being silent online as they took time to complete course-related activities not visible on the forum, such as doing research, playing with ideas, crafting responses in preparation to post, reading course materials, and observing and listening.

Silence online was also a time for participants to be watchful and ensure understanding of the direction the dialogue was headed before they posted-that is, to ensure that the voice they were adding was a harmonious one. This behaviour parallels Gradinaru's (2016) observation that silences occur in online communities when members are disinclined to express a viewpoint that does not align with the majority.

\section{Theme 2: Learners Absorb Silence From Others}

Participants described a wide variety of feelings they experienced when they met silence online from other people. Many of the participants described the experience of silence from others as being unpleasant and lingering, while a few others acknowledged the silence but dismissed its effect on them. The verb absorb used in this theme's title captures the nature of both of these experiences. The New Oxford American Dictionary's (Apple, Inc., 2016) definition of absorb includes the idea of taking something in and then either soaking it up (lingering) or reducing the effect or intensity of it (dismissing the effect).

Silence coming from others online could produce feelings of awkwardness and uncertainty or wondering if one had said something that caused offense. These times of meeting silence from others could be a source of feeling devalued, isolated, frustrated, or discouraged. Silences from others were particularly noted during 
small-group work and when the discussion related to high-stakes assignments-findings echoed in other research (Mattsson, Karlsson, \&Lindström, 2008; Mico-Wentworth, 2014).

Not all online silences from others were met with negativity. Some participants described feeling neutral about silences online, that the silence was either expected or of no consequence; others commented that silences coming from others online were a source of building resilience.

Many of the participants described silence from instructors as being particularly memorable. The participants generally held instructors in high regard as persons of authority-regard that was sometimes lost if the instructor failed to answer a direct question or answered it in a manner that left the learner feeling unheard or effectively silenced.

During periods of learner conflict online, participants spoke of wanting instructors to step in to mediate. Participants valued clarity on expectations for the number of posts and expressed appreciation when instructors spoke out to keep the dialogue on task and to offer additional ideas or references for the group to consider. The importance of the instructor role in setting a respectful tone of dialogue online, defining clear expectations, and maintaining a regular presence in the learning environment to encourage learners and redirect dialogue when needed is supported by other research (Bates, 2015; Coppola, Hiltz, \& Rotter, 2002; Weaver \&Albion, 2005).

\section{Theme 3: Learners Perceive, and Use, Silence as Demarcation}

The third theme that emerged was one of silence being experienced as a border-that is, a demarcation between distinct spaces. This theme manifested in two ways: one was experienced as participants prepared to speak out, and another came into play as the online discussion unfolded. Participants described experiencing silence as something that needed to be crossed over as a means to enter the discussion. Once participants were engaged in the discussion, they described silence as a boundary that defined and contained appropriate decorum and content within the online forums; it was a responsive action towards others who crossed lines of acceptable behaviour.

Participants made decisions whether to cross the borders of silence into zones of participation for different reasons, and with varied motivations and differing levels of willingness behind them. They expressed differing feelings brought on while making this crossing. Some participants felt safe doing this. Some revealed that they felt more comfortable speaking out in the online classroom than in a bricks-and-mortar one. Several of the participants described how familiarity with the discussion topic eased their crossing out of silence and made it feel easier to participate, a finding supported by others (Hew, Cheung, \& Ng, 2010; Tu \& McIsaac, 2010).

Participants described certain border crossings out of silence as being effortful, intimidating, or daunting. Some participants emphasized that they would have preferred to stay silent but that they felt "pushed" to speak out on in a discussion by course requirements mandating a certain number of posts. These participants wanted to be able to interact with course content without being required to interact with other participants. The idea that students do learn by reading messages posted by others, even if they do not respond to them, is corroborated by Antonacci (2011) and Sutton (2001). 
Silence as boundary enforcement. Silence was also used to demarcate boundary lines within the online discourse. This manifestation of silence is a variation on silence as a means of, as discussed in the first theme-specifically, participants enacted silence online as a means of enforcing norms of social and academic behaviour in the discussion forums.

Silence was used in the online discussion forum as a way to contain conversation and behaviour, and this use of silence was implicitly recognized and understood by the participants. It was in essence an online version of giving people "the silent treatment." Boundary lines of silence were put up by both instructors and learners to maintain appropriate academic behaviour and discourse.

At times, the participants experienced instructors using silence as a means of steering a discussion away from particular topics or tangents, a strategy that was sometimes contested by the learners. Many online courses are designed following social constructivist principles, which encourage learners to become cocreators of knowledge (Bates, 2015; Rovai, 2004). Theaim is a transition from theinstructor's voice being the one of authority to the learners finding their own voices. At times, this process unfolded in awkward, rough movement patterns between those whose voices might be silenced and those whose voices might be allowed to prevail in the online discussion.

\section{Theme 4: Learners Experience Silence Within Voice}

Another theme that emerged was that it is possible for silence to exist within voice online. Silence and voice are not two distinct and opposing entities. Participants frequently described instances of holding some things back or being ambiguous in their online posts, in effect "muffling" their voices online. Participants also described scenarios in which they felt the presence of silence lingering, despite having received responses from others.

These participant experiences highlight that silence and voice are not binary opposites. Silence and voice can coexist; silence can be present within voice online. Muñoz (2014) reflects that "what we experience and describeas 'silence' is often, in fact, written or spoken activity that leaves something relevant unsaid" (p. 15). This aspect of online silence was manifest in participants being nonspecific about personal details that may be criticized by others, glossing over topics that might be controversial or might spark strong reactions from others, or not committing to a firm position on a topic. Yet, it was also present when an unhelpful response from an instructor made participants feel that they had not truly been listened to, or "heard," as well as when learners experienced the words of another person, which did not reflect how they were feeling or thinking, being put into their mouths. When a representative spoke out as if on behalf of the whole group, the voices of the silently dissenting others were drowned out or silenced by the words of one.

Collectively, these examples contribute to the theme of lived experiences that are neither fully silence nor voice. To the casual reader, a dialogue may appear to be occurring in the discussion threads that are unfolding, but silence is present, concealed by the visible written words. 


\section{Theme 5: Learners Use Deliberate, Complex Strategies While Engaging in Online Discourse}

Coming out of silence to engage in online discourse was not something that was done lightly by the participants, who deliberated about the numbers of posts they should make and the threads to which they would reply; only then did they carefully craft the content of their responses. This theme relates to experiences with the mechanics of entering and sustaining online discourse.

Participants deliberated on a variety of factors in the process of composing posts, including maintaining professionalism, offering content of value, and using strategies to engage their peers and further the dialogue. As they monitored the unfolding dialogue, participants were aware of which of their cohort members met only the minimum expectations for participation. Some described meeting the targets for the minimal number of posts as a way of managing the competing priorities of the demands of their courses, work, and homelife.

While some of the participants recounted writing posts as a stressful process, others found composing their thoughts in writing to be easier than speaking them out loud. Participants more readily responded when they felt passionate about a topic and when they felt they could add a meaningful contribution to the discussion.

The participants described how they went about selecting discussion threads to which to respond. The level of connection they had with the other person posting, the amount of authority that a certain voice carried in the online classroom, social courtesy, and the length and format of the post awaiting a reply all contributed to decisions the participants made about whether or not to reply to a specific post. Participants explicitly or implicitly spoke of voices that they perceived as carrying authority in the online discussions, including those of the instructor and peers who had relevant life experience or a clear vision of how a group project might unfold.

Participants described making considered deliberations in crafting the content and tone of their posts. They recounted efforts to maintain a professional tone in their writing, to use strategies intended to encourage responses from others, and to add value to the dialogue. The perceived permanency of the written comments shaped awareness of how posts were crafted. Participants also described strategies they used to extend dialogue in the discussion threads. Continuation of dialogue was important for the participants to feel that the online discussion was a beneficial one. Comments that merely stated agreement or shared a phatic anecdote did not sufficiently further the discussion. Participants appreciated responses that built on points that they had raised and contained one or two new ideas for consideration. They described being disinclined to respond to rambling or overly lengthy posts.

\section{Theme 6: Learners Hear Each Other in a Trusted Community}

Participants described the asynchronous online dialogue as feeling stilted and awkward at times, yet they also described moments that the discourse transcended temporal and spatial disruption to feel more natural, even spirited and playful. In these transcendent moments, participants felt that their voices had been truly heard online. These moments occurred when the online learning community was functioning well and its members were supporting each other and contributing to the dialogue, as well as when learners 
could talk about subjects online that they could not talk about in their day-to-day lives because no one was interested.

Participants described experiences they had in the asynchronous discussion that gave them an energized, connected feeling. These experiences were memorable ones for the participants, who described them as times of spontaneity, fun, and excitement that felt less stilted and more like a real-time conversation. Sometimes these moments involved a topic that was energizing and interesting to the participants. Other times, instructors elicited these moments through the skilled use of technology, such as by posting short, recently made videos that added immediacy and personality to the online environment.

Participants described feeling heard online when others responded to them by building on specific points they had raised, addressed them by name in the forum, recognized their expertise, and wrote replies that were thoughtful and respectful. Some participants described their efforts to attend to posts that had not received any replies out of concern for the feelings of the post's author. Participants felt an overall feeling of safety in the online environment of the discussion forums.

When online spaces have dialogue that feels spontaneous, natural, spirited, and open, and the online environment feels like a safe communal place where one can share ideas and be heard, online silence can be transcended.

\section{Implications for Distance Education}

While the findings of a phenomenological study are not meant to be generalized, van Manen (2014) argues that they should "foster and strengthen...thoughtful and tactful action" (p. 15). Some of this study's findings may be helpful for those in the distance education community, including educators, learners, and curriculum developers.

Recognizing that learners enact purposeful silences may help instructors to recognize that though learner silence online may appear as nonparticipation, learners may be busy with a great deal of course-related activity during those silences, as described by this study's participants. Learners described being engaged in activities such as researching, reflecting, composing thoughtful posts, and following the ongoing discussion with interest. Participants in this study did not criticize "lurking" behaviour in others and offered reasons for why they might elect to watch or listen without posting.

All members of distance learning communities should be mindful that the word lurking, while commonly used, is not a neutral word. Indeed, the word has negative connotations; the New Oxford American English Dictionary (Apple, Inc., 2016) defines a lurker as one who is waiting "in ambush for something" or one who is present in a barely discernable but "unpleasant" and "threatening" manner. Recognizing the negative undercurrent in the word, instructors and learners may choose to use alternate words, such as listening or vicarious interacting, that have more positive implications.

Learners who experience silence from others may have mixed reactions to that silence. At times, silence from others may be innocuous, but other times, silences feel demeaning. A strongmessage from the findings 
is that participants valued hearing the instructor's voice, especially when the interactions were timely and helped to further thelearning. Participants looked for instructor intervention when conflict emerged online. They appreciated instructor proficiency with the learning management system and instructor innovations that added immediacy to the dialogue, such as posting just-in-time videos that clarified teaching points or offered encouragement.

The theme of silence being present within voice raises several recommendations for distance instructors and learners. Instructors and learners should ensure they have "heard" the intent of questions that are posed to them and that the answers they provide address the intended question. Learners may feel unintentionally silenced by answers they receive that do not specifically address the questions they asked. Instructors and learners who are contributing to teaching presence need to be mindful to listen for silences online - that is, to pay attention to things that may be "unsaid" and reflect on whether or not some action is needed to allow learners to speak with full voices.

Instructors should be aware that the action of speaking out in online discussions is not done lightly. Learners described putting a great deal of thought into crafting their posts and monitoring their word choices. Curriculum designers may also need to rethink mandatory requirements for posting frequency. Several of the learners in this study remarked that they felt pressure at times to speak out even when they had nothing of value to contribute. At times, they felt that they were not allowed to learn just by listening and following the ongoing dialogue. Creative curriculum design should allow learners choice in which dialogues they engage, allow them to discuss topics that are both meaningful and relevant to their learning needs and context, and allow for times of learning through listening and vicarious interaction. When learners feel safe and heard in the online community, they feel freer to take risks in expressing their ideas. In this study, feelings of spontaneity and responsiveness heightened engagement and helped the online dialogue to feel more like a face-to-face conversation.

Finally, the theme of silence as demarcation invites members of distance learning communities to reflect on when they have intentionally or unintentionally drawn "boundary lines" in online classrooms. What norms are being enforced by those boundaries? As online discourse unfolds, are there certain ideas or voices being silenced that perhaps do not need to be? These are not easy questions to answer; they will require ongoing reflection by members of the learning community.

\section{Limitations and Delimitations}

Limitations of this study include limitations of the approach. By its nature, phenomenology does not generate findings that are generalizable to a larger population, nor is the intent to generate theory or conceptual models to explain the phenomena under study. Delimitations are that the study does not include instructor perspectives on online silence, although instructors are a key component of the online learning environment. The study also excluded the experience of silence during massive open online courses and other non-cohort-based distance programs of study. It also did not intentionally seek out voices of learners from demographic groups at risk of marginalization. These boundaries contained the scope of the proposed research and create opportunities for future research. 


\section{Conclusion}

The aim of this phenomenology of practice study was to gain new insights into, and a more thoughtful understanding of, distance learners' experiences of silence online. The six emergent themes described in this study reinforce that silence online is a complex and polymorphous entity. Silence online is not merely the absence of visible participation. When distance learners enact and encounter silence online, they experience a dynamic and shape-shifting phenomenon. At times, online learners may be silent, but they also use silence, they break through silence, and having broken through it, they may meet it again in the online discussion forums.

Silence may be a time of observing and listening, as well as a means of deferring actions that are visible in the online environment in order to do something else. Learners experience silence as both a means and an end for enforcing decorum and appropriate speech in the discussion forums.

Silence and voice are not distinct opposites. Silence can linger in textual voice; written words may mask the silence of truths left unspoken. Learners may use vague or imprecise words to tread between silence and voice, expressing certain carefully selected words or thoughts but intentionally keeping others left unsaid. Poorly chosen words posted in an inattentive response can sting their recipient as silence. Yet despite the polymorphous properties of online silence, it can be transcended by strength of connection, responsiveness, and a feeling of safety in the online environment. 


\section{References}

Adams, C., \& van Manen, M. (2006). Embodiment, virtual space, temporality and interpersonal relations in online writing. College Quarterly, 9(4), 1-18. Retrieved from http:// www.maxvanmanen.com/files/ 2011/ 04/2007-Embodiment-Virtual-Space.pdf

Angen, M. J . (2000). Evaluating interpretive inquiry: Reviewing the validity debate and opening the dialogue. Qualitative Health Research, 10(3), 378-395. https:// doi.org/ 10.1177/ 104973230001000308

Antonacci, D. M. (2011). The influence of direct instruction on asynchronous educational discussions (Doctoral dissertation, University of Missouri-Columbia). https:// doi.org/ 10.32469/10355/ 14389

Apple, Inc. (2016). New Oxford American dictionary (2.2.1 for OS X) [Mobile application software].

Bates, A. T. (2015). Teaching in a digital age: Guidelines for designing teaching and learning. Tony Bates Associates Limited. Retrieved from https:// opentextbc.ca/ teachinginadigitalage/

Bazeley, P. (2009). Analysing qualitative data: More than "identifying themes." Malaysian J ournal of Qualitative Research, 2(2), 6-22. Retrieved from http:// www.researchsupport.com.au/Bazeley_MJ QR 2009.pdf

Beaudoin, M. F. (2002). Learning or lurking? Tracking the "invisible" online student. The Internet and Higher Education, 5, 147-155. https:// doi.org/ 10.1016/ S1096-7516(02)00086-6

Benfield, G. (2000). Teaching on the Web-Exploring the meanings of silence. Retrieved from http:// pandora.nla.gov.au/pan/10088/200108160000/ultibase.rmit.edu.au/Articles/online/benfield1.htm

Brown, E. K. (2011). Safe spaces in online learning: The role of faculty perceptions in design and practice (Doctoral dissertation, University of Georgia). Retrieved from https://getd.libs.uga.edu/pdfs/brown_eric_k 201105 phd.pdf

Conrad, D. (2002). Community, social presence and engagement in online learning (Unpublished doctoral dissertation). University of Alberta, Edmonton, Alberta. Retrieved from http:// www.collectionscanada.gc.ca/ obj/s4/f2/ dsk4/ etd/NQ81174.PDF

Conrad, D. (2014). Interaction and communication in online learning communities: Toward an engaged and flexible future. In O. Zawacki-Richter \& T. Anderson (Eds.), Online distance education: Towards a research agenda (pp. 381-402). Athabasca, AB: Athabasca University Press. https:// doi.org/ 10.15215/aupress/9781927356623.01 
Coppola, N. W., Hiltz, S. R., \& Rotter, N. G. (2002). Becoming a virtual professor: Pedagogical roles and asynchronous learning networks. J ournal of Management Information Systems, 18, 169-189. https:// doi.org/ 10.1080/07421222.2002.11045703

Creswell, J .W. (2013). Qualitative inquiry and research design: Choosing among five approaches. Los Angeles, CA: Sage Publications.

Dukes, S. (1984). Phenomenological methodology in the human sciences. J ournal of Religion and Health, 23(3), 197-203. https:// doi.org/10.1007/BF00990785

Fritz, H. (1997). Host contacted, waiting for reply. In U. Bernath \&E. Rubin (Eds.), Final report and documentation of the virtual seminar for professional development in distance education (pp. 355-378). Oldenburg, Germany: Bibliotecks und Informations-systems der Universitat Oldenburg.

Gradinaru, C. (2016). The metaphor of "voice" in computer-mediated communication. Agathos, 7(2), 121133. Retrieved from https:// www.ingentaconnect.com/content/ doaj/20691025/2016/00000007/00000002/art000 $\underline{08}$

Hew, K. F., Cheung, W. S., \&Ng, C. S. L. (2010). Student contribution in asynchronous online discussion: A review of the research and empirical exploration. Instructional Science, 38(6), 571-606. Retrieved from http:// www.jstor.org/stable/23372901

Koro-Ljungberg, M., Yendol-Hoppey, D., Smith, J . J ., \& Hayes, S. B. (2009). (E)pistemological awareness, instantiation of methods, and uninformed methodological ambiguity in qualitative research projects. Educational Researcher, 38(9), 687-699. https:// doi.org/ 10.3102/0013189X09351980

Kreijns, K., Kirschner, P. A., \&J ochems, W. (2003). Identifying the pitfalls for social interaction in computer-supported collaborative learning environments: A review of the research. Computers in Human Behavior, 19, 335-353. https:// doi.org/10.1016/S0747-5632(02)00057-2

LeVasseur, J . J . (2003). The problem of bracketing in phenomenology. Qualitative Health Research, 13(3), 408-420. https:// doi.org/ 10.1177/ 1049732302250337

Mattsson, A., Karlsson, M., \& Lindström, B. (2008). Silence on the Net. Distance education design in a CSCL and community of practice framework. In K. McFerrin, R. Weber, R. Carlsen, \& D. Willis (Eds.), Proceedings of SITE 2008-Society for Information Technology \& Teacher Education International Conference (pp. 549-556). Las Vegas, NV: Association for the Advancement of Computing in Education. Retrieved from https:// www.learntechlib.org/ primary/p/27224/

McPherson, G., \& Thorne, S. (2006). Exploiting exceptions to enhance interpretive qualitative health research: Insights from a study of cancer communication. International J ournal of Qualitative Methods, 5(2), 73-86. https:// doi.org/ 10.1177/ 160940690600500210 
Mico-Wentworth, J . M. (2014). Cultural concept: Is silence golden? (Order No. 1572278). Available from ProQuest Dissertations \& Theses Global. (1650585398). Retrieved from http:// ezproxy.library.ubc.ca/login?url=https:// search-proquestcom.ezproxy.library.ubc.ca/ docview/ 1650585398?accountid=14656

Muñoz, K. L. (2014). Transcribing silence: Culture, relationships, communication. Walnut Creek, CA: Left Coast Press.

Rovai, A. P. (2004). A constructivist approach to online college learning. The Internet and Higher Education, 7(2), 79-93. https:// doi.org/ 10.1016/j.iheduc.2003.10.002

Sutton, L. A. (2001). The principle of vicarious interaction in computer-mediated communications. International J ournal of Educational Telecommunications, 7(3), 223-242. Retrieved from https:// www.learntechlib.org/primary/p/9534/

Taylor, J . C. (2002, October). Automating e-learning: The higher education revolution. In GI Jahrestagung (pp. 64-82). Berlin: Springer. Retrieved from https:// pdfs.semanticscholar.org/ 1a83/ ebdebfed9966f4051c93351953907d99aac7.pdf

Tu, C. H., \& McIsaac, M. (2010). The relationship of social presence and interaction in online classes. American J ournal of Distance Education, 16(3), 131-150. https:// doi.org/ 10.1207/S15389286AJ DE1603_2

Vagle, M. D. (2014). Crafting phenomenological research. Walnut Creek, CA: Left Coast Press.

van Manen, M. (1990). Researching lived experience: Human science for an action sensitive pedagogy. Albany, NY: State University of New York Press.

van Manen, M. (2011). Orientations in phenomenology. Retrieved from http:// www.phenomenologyonline.com/inquiry/ orientations-in-phenomenology/

van Manen, M. (2014). Phenomenology of practice. Walnut Creek, CA: Left Coast Press.

Weaver, C. M., \&Albion, P. (2005). Momentum in online discussions: The effect of social presence on motivation for participation. In H. Goss (Ed.), Balance, fidelity, mobility: Maintaining the momentum? Proceedings of ASCILITE 2005: 22nd Annual Conference of the Australasian Society for Computers in Learning in Tertiary Education (pp. 703-706). Brisbane, Australia: Queensland University of Technology, Teaching and Learning Support Services. Retrieved from https:// eprints.usq.edu.au/690/1/ weaver_albion.pdf

Xin, C., \&Feenberg, A. (2006). Pedagogy in cyberspace: The dynamics of online discourse. J ournal of Distance Education, 21(2), 1-25. https:// doi.org/ 10.2304/ elea.2007.4.4.415

Zembylas, N., \&Vrasidas, C. (2007). Listening for silence in text-based, online encounters. Distance Education, 28(1), 5-24. https:// doi.org/ 10.1080/01587910701305285 
Distance Learners' Experiences of Silence Online: A Phenomenological Inquiry

Duran

Athabasca

University

(c) 